\title{
A Study on University Students' Satisfaction with an Online Course Jixin Pan ${ }^{1, a}$ and Chen $\mathrm{Li}^{1, \mathrm{~b}}$

\author{
${ }^{1,2}$ Modern Educational Technology Center North China Institute of Science and Technology
} \\ Yanjiao, China, 15350719831 \\ apjx2007_0310@163.com
}

Keyword: College students; Online course; Satisfaction

\begin{abstract}
The paper takes an online course Introduction to Internet and web technology as an example, adopting the method of combining questionnaire survey of the network course platform with interviews and statistical analysis of SPSS software, to explore the university students' satisfaction with an online course. The research found that university students expressed satisfactory attitude towards an online course on the whole; the satisfaction with an online course for girls is slightly higher than for boys; there is no essential difference between students of different gender. But there still exists some problems: students can't be self-disciplined without the restrains of the classroom teaching; lack of learning atmosphere and a sense of loneliness; insufficient resources, difficulties in sharing; delayed interaction, slow feedbacks and so on.
\end{abstract}

\section{Questions and the Research Significance}

The Educational Informatization 10-year Development Plan (2011-2020) indicates that the Chinese government will establish high-quality digital educational resources and build a shared environment, and support the intercollegiate elective network courses and resources sharing activities, and develop 20,000 high-quality network courses and constantly update quality digital resources to meet the needs of all types of education at all levels [1]. Of all kinds of resources of colleges and universities, course resources are the basic resources. In the information age, the network course is an important part of course resources. Dean Professor Chen Geng in College of Distance and Continuing Education, Beijing Transportation University, who based on his own practical experience, pointed out that the examination of the courses should have unified syllabus and uniform requirements so that achieving the sharing of course resources can be easier. General education curriculum is the basic course that can broaden students' views and cultivate students' perfect personality by the fundamentality, completeness, comprehensiveness and extensiveness of knowledge [2]. And elective course is the focus of reform of general education in universities. It is also the most widely coverage kind of courses in practice and meet the above characteristics. Therefore, this paper takes the Introduction to Internet and web technology, a network general education elective course, as an example to investigate and analyze college students' satisfaction with an online course and puts forward the corresponding strategies to solve the existing problems so as to provide reference and guidance for the follow-up study.

\section{Literature Review}

Since Packard proposed the concept of general education in the early nineteenth Century, general education has gradually become an important part of higher education. In the United States, Japan, Singapore and other countries, research on the general education is very successful, and there has been a pattern of "all kinds flowers blooming together, contending of a hundred schools of thoughts", especially in the United States. For example, the "Core Curriculum System" at the Harvard University, the "Great Classics Plan" at the University of Chicago, a set of must-read courses and teaching materials developed by Columbia University. In China, Taiwan and HongKong are leaders in the 
general education research. As early as in 1984, Taiwan General Education Institute was formally established, Journal of general education was published and professional meeting was organized to discuss the research on general education every year. At the same time, research on the general education in main land China also became a hot topic among scholars. Based on the domestic related literatures on general education, the authors found that the current research in general education mainly focus on the following aspects: (1) research on the relevant theoretical research in the general education, such as the historical revolution, concept and connotation, nature and characteristics, the level and structure, methods and principles; (2) research on practical exploration and experience introduction of general education, such as practical work and survey analysis, current situation and reflection, problems and strategies; (3) research on the forms of general education and evaluation methods; such as the research and evaluation of general education curriculum; (4) comparative research on general education and other education, such as professional education, generalist education, liberal education and so on[3][4][5][6].

General education curriculum is a basic practice form of general education. At present, the studies on general course abroad not only attach importance to theoretical research, but also pay attention to the practical exploration. Seen from the teaching of general courses carried out in the United States universities, general education curriculum has a diversified development trend in teaching. Researches on general education curriculum in the domestic were in full swing. Li (2007) took 9 key universities as examples to survey and study present situation of general education curriculum [7]. Pang (2010) pointed out that three major difficulties restricted construction and development of general education in universities in China [8]. Based on previous studies, a review of general education curriculum development in the past twenty years in China was made by Feng (2012) [9]. Lv \& Wang (2012) investigated the situation of College Students' satisfaction of curriculum plan, resources, teaching, evaluation and other aspects, and analysed basic situation of the learning input and learning gains [10]. $\mathrm{Li}$ Ying et al. (2012) explored general education curriculum from aspects of development and assessment methods [11].

To sum up, as a teaching idea and the education thought, general education has been integrated into the higher education culture. However, the understanding of the general education is shallow, and there are few in-depth case analyses, and there are more macro researches than micro researches. Compared with researches on other respects of general education, and there are few researches on the teaching of general education curriculum. Although the researches on general education curriculum system, structure, form, construction and implementation have been involved in China, few people study it from details. Therefore, this paper mainly takes network general education elective course as an example to broaden the scope of the research on general education.

\section{Research and Design}

Introduction to the Object of Study. Introduction to Internet and web technology is a type of mature network general education elective courses in our university. From April 1, 2013, to May 31, 2013, the course lasted for two months, a total of 8 weeks. Mixed learning pattern was adopted. Classroom teaching was used in the guidance of curriculum, including the pre-class guidance and instruments of platform. The pattern of network platform was mainly in the teaching of curriculum. Teachers taught on every Wednesday afternoon. Learners can enter the network platform to continue to study and discuss content of course in the spare time. There are 185 students, 1 lecture, 1 teaching assistant and several research assistants in the class. The research assistants registered in the name of student status and tracked the whole process of the study, but they did not discuss in class forum. The course took students' online learning time, number of submitted homework and number of questions online as important curriculum evaluation. Students must complete 32 hours of credits as required. And students' 
learning hour, times of discussion in the forum, times of answering questions and submitting homework are specifically required. Basic information was shown in table 1.

Table 1 Basic Information of the Curriculum

\begin{tabular}{|c|c|}
\hline Course & $\begin{array}{c}\text { Introduction to Internet and web } \\
\text { technology }\end{array}$ \\
\hline Nature & 32 \\
\hline Hours & 2 \\
\hline Credit & test \\
\hline Assessment method & 3 \\
\hline Number of submitted homework & 20 \\
\hline Online learning time & $>4$ \\
\hline Number of questions & \\
\hline
\end{tabular}

The Questionnaire and Scale. The preparation of questionnaire

Questionnaire is made by the method of combining reading the relevant literature and local interviews. Designing questionnaire combined with the basic framework of our network courses with the issue that students are concerned about. And it asked opinions of relevant management personnel, teachers and students many times. The questionnaire is divided into three parts: the first part is the basic information of the respondents, it is aimed at knowing about respondents' identity; the second part is the main index of surveying satisfaction, it is the subject, including curriculum guide (1-5), curriculum resources (6-10), test tools (11-15), teachers resources (16-20), exchanges feedback (21-25) and the whole curriculum (26-30) 6 levels in all. Each level contains five items, a total of 30 items. All items were investigated by Li Kete five point scales. Five options for each index were given 5, 4, 3, 2, 1 points, which are very satisfied, satisfied respectively, in general, not satisfied, very dissatisfied The Third part is open questions, the purpose of this part is to let the respondents speak out one's mind freely and collect students' comments and suggestions on the current network general education elective course from different perspectives. After finishing the questionnaire, we let two experts with a background in information technology education give some suggestions on classification of topics, choice of words and appropriateness of the words and content.

Analysis of reliability and validity

In statistical analysis of SPSS, cloning Bach coefficient (Cronbach's a) is usually used to test the internal consistency of scale items. After reliability test of questionnaire, all levels of a coefficient is more than 0.729, which indicates that the internal consistency of scale is relatively higher. At the same time, the method of factor analysis is used to measure the validity of questionnaire in this study. And it measures KMO value is 0.894 . Bartlett sphere test is the null hypothesis, $p=0.000<0.001$, which ensures that the questionnaire has good structure validity.

The Results of Data Analysis

Analysis of descriptive statistics

The students filled in the questionnaire anonymously according to their own will. The basic information of sample was shown in table 2 . 
Table 2 Demographic Information of Survey

\begin{tabular}{|c|c|c|c|}
\hline & Items & Number & Percentage (\%) \\
\hline \multirow{3}{*}{ Gender } & Male & 76 & 62.3 \\
\cline { 2 - 4 } & Female & 46 & 37.7 \\
\hline \multirow{4}{*}{ Glass } & Freshman & 49 & 40.2 \\
\cline { 2 - 4 } & Sophomore & 38 & 31.1 \\
\cline { 2 - 4 } & Junior & 28 & 23.0 \\
\cline { 2 - 4 } & Senior & 7 & 5.7 \\
\hline
\end{tabular}

It can be concluded from table 2 that the number of boy is more than girl's in 122 people who participated in the survey, and its proportion is nearly 2:1. That our institute is a college of science and engineering has a certain relationship with this result. The fresher is the largest number; the following is sophomore and junior. The senior is the least. On the one hand, this reflects the basic situation with the curriculum; on the other hand, this course is an elective course, and this may lead to this consequence.

Table 3 Statistics on Different Levels of Analysis

\begin{tabular}{|c|c|c|}
\hline & Mean & Std. Deviation \\
\hline Curriculum guidance & 4.04 & .66 \\
\hline Curriculum Resources & 3.93 & .64 \\
\hline Testing tool & 4.07 & .57 \\
\hline Teachers resources & 4.25 & .68 \\
\hline Communication feedback & 4.02 & .67 \\
\hline Whole curriculum & 4.18 & .67 \\
\hline
\end{tabular}

The table 3 gives the respondents' mean value and standard deviation in six levels of curriculum guidance, curriculum resources, testing tools, teacher resources, communication feedback and the whole curriculum. In Li Kete's five point scale, the median was 3, a percentage $=(\mathrm{M}-1) /($ point- 1$)=$ $(3-1) /(5-1)=50 \%$, which shows that subjects' satisfaction is about 50\%. If the average number of items score in 3.9 above, percentage of overall satisfaction $(3.9-1) /(5-1)=72.5 \%$, which shows subjects overall satisfactory.

Correlation analysis

In order to detect whether the scale between the various levels have significant correlation, the coefficient of determination that is created by statistician K. Pearson to test. R2 coefficient indicates that the first variable can explain the number of variable number, or second variable can explain how much variance the first variable have. Generally, when the $\mathrm{R} 2<0.16$, it shows the low correlation between variables; when $0.16 \leq \mathrm{R} 2 \leq 0.49$, it shows moderate correlation variables; when R2 $>0.49$, it shows high correlation between variables. The positive correlation coefficient value shows positive correlation between two variables; the negative correlation coefficient value shows negative correlation between two variables. Taking the curriculum guidance and curriculum resources as an example, the coefficient of determination between two variables is 0.53 , which shows the variables of the course guiding can explain $53 \%$ of the total variance of curriculum resource variables. $\mathrm{P}<0.01$, the relationship between the two is a highly positive correlation.

Test of the average difference--T test 
In order to analyze whether there is a significant between different gender students' satisfaction on every level, Independent samples T test in SPSS statistical analysis is used to affirm in this study, as shown in table 4.

Table 4 Differences between Different Gender Students in the Satisfaction at All Levels

\begin{tabular}{|c|c|c|c|c|c|c|}
\hline & Gender & $\mathrm{N}$ & Mean & $\begin{array}{c}\text { Std. } \\
\text { Deviation }\end{array}$ & $\mathrm{t}$ & $\begin{array}{l}\text { Sig. }(2- \\
\text { tailed) }\end{array}$ \\
\hline \multirow{2}{*}{$\begin{array}{l}\text { Curriculum } \\
\text { guidance }\end{array}$} & Male & 76 & 3.97 & 0.86 & \multirow{2}{*}{-1.18} & \multirow{2}{*}{0.33} \\
\hline & Female & 46 & 4.16 & 0.78 & & \\
\hline \multirow{2}{*}{$\begin{array}{l}\text { Curriculum } \\
\text { Resources }\end{array}$} & Male & 76 & 3.84 & 0.89 & \multirow{2}{*}{-1.47} & \multirow{2}{*}{0.25} \\
\hline & Female & 46 & 4.07 & 0.79 & & \\
\hline \multirow{2}{*}{ Testing tool } & Male & 76 & 4.10 & 0.78 & \multirow{2}{*}{0.48} & \multirow{2}{*}{0.50} \\
\hline & Female & 46 & 4.02 & 0.88 & & \\
\hline \multirow{2}{*}{ Teachers resources } & Male & 76 & 4.21 & 0.83 & \multirow{2}{*}{-0.56} & \multirow{2}{*}{0.60} \\
\hline & Female & 46 & 4.30 & 0.75 & & \\
\hline \multirow{2}{*}{$\begin{array}{c}\text { Communication } \\
\text { feedback }\end{array}$} & Male & 76 & 4.03 & 0.92 & \multirow{2}{*}{-0.12} & \multirow{2}{*}{0.64} \\
\hline & Female & 46 & 4.02 & 0.90 & & \\
\hline \multirow{2}{*}{ Whole curriculum } & Male & 76 & 4.12 & 0.84 & \multirow{2}{*}{-1.07} & \multirow{2}{*}{0.36} \\
\hline & Female & 46 & 4.27 & 0.70 & & \\
\hline
\end{tabular}

As can be seen from the table 4, girls' satisfaction is higher than boys' in the levels of guidance of curriculum, curriculum resources, teacher resources and the whole course, both of which are more than the intermediate value 3 of the five point scale, namely, achieving satisfactory degree. In addition, there are some differences between boys' and girls' groups, but the difference between boys is bigger than girls, and the difference is not obvious. The students of different genders don't have significant differences in the levels of guidance of curriculum, curriculum resources, teacher resources and the whole course $(\mathrm{t}=1.18$, sig. $=0.33>0.05 ; \mathrm{t}=-1.47$, sig. $=0.25>0.05 ; \mathrm{t}=-0.56$, sig. $=0.60>0.05 ; \mathrm{t}=-1.07$, sig. $=0.36>0.05$ ). From the analysis of the survey items, "I think the knowledge system of the courses complete, and reflect advance of subject (A7)" ( sig. =0.027) and "I think curriculum resources abundant (A10)" ( sig. =0.01) the two kinds sig values are less than 0.05 and reached significant level. It shows the students of different genders have different views of "the knowledge system of the courses" and 'curriculum resources", and girls' are lower than boys' in the overall difference. In addition, the degree of satisfaction with the boys is higher than girls in the levels of testing tool and the feedback of communication, both of which are higher than the intermediate value 3 of the five point scale. Furthermore, there are some differences between boys' and girls' groups, but the difference is not obvious. The students of different genders don't have significant difference in the levels of testing tools and the feedback of communication $(\mathrm{t}=0.48$, sig. $=0.50>0.05 ; \mathrm{t}=-0.1156$, sig. $=0.64>0.05)$.

On the whole, there is no essential difference between different gender students in the satisfaction with the network course. The girls' satisfaction with the network course is slightly higher than the boys' (except the levels of testing tools and feedback of the communication). In addition to boys' and girls' expression in item seven and item 10 in the scale, there were no significant differences in other items.

\section{Analysis of Questionnaire with Open Questions}

The 31th and 32th questions in the questionnaire we set up the open test questions, survey on the difficulty in network courses of general learning process as well as suggestions on the course. Although the network learning and teaching space separation can be achieved and meet the demands of general education. However, the survey found what students reflect more is that they can't get teachers to guide which causes problems, such as the in-depth study, the completion of operations, the grasp of main and 
difficult content, the students' self-control, and communication barriers and so on. There exist some common problems: the degree of adaptation of the learning environment, for example, some students think they feel lonely without a learning atmosphere, "like a fly without head". There are comprehensive quality problems. The students expressed that they don't have enough knowledge of the webpage, and there are many misunderstanding. The students also complained that their basic skills of computer were poor, and they were often discouraged by the difficulties. They also have difficulty in interactive activities. Some students find that they cannot get the teachers' face to face guidance. Some students suggest that they hope that there are organized regular communication meetings with the teacher. They expressed the hope that there should be some face-to-face teaching during the course. Some students think that "it is not convenient for them to take notes, and it's hard to follow the page". Some students expressed that "sometimes we don't ask questions during class time, sometimes because students ask too much, so we can't get promptly reply", etc.

From the investigation of this network curriculum the study concludes that students lack enough understanding to the arrangement of the course, and some students lack basic skills related to the study of the course. The study also found that with the influence of the traditional classroom teaching, some students could not adapt to the network learning, and could not find a sense of belonging in the network environment. Of course, the network curriculum resources and platform also exist some problems, such as the richness of resources and the adaptability of the platform, etc. In addition, there are some deficiencies in the curriculum design of teachers as well as the implementation, management and evaluation of teaching.

\section{Conclusion}

General education is different from classical education and professional education. With the rise of network teaching, general education has its unique role in changing the traditional teaching. Network curriculum can not only add new vitality to educational and teaching reform in higher school, but also create a new philosophy of education. This paper attempts to find the breakthrough between information technology and general education. From the angle of the network courses, this paper analyzed the current situation in depth, pointed out the dilemma and its outlet with an intention to innovate the present general education. The implementation of general education is a comprehensive project, and by examining the experience in the United States, Japan and other countries who are successful in development of general education, we can say that there is still a long way to go for the higher education institutions in China.

\section{References}

[1] Chinese People's Republic of China Ministry of Education. Education Informationalization Ten Year Development Plan (2011-2020) [EB/OL]. Retrieved from: http://www.edu.cn/html/info/10plan/ghfb.shtml. 2014-05-09.

[2] Pang, Haishao, "The Difficult Situation of the Construction of General Education Curriculum," Jiangsu Higher Education, Vol. 26, No. 2, pp. 63-66, April 2010.

[3] Zhang, Shousong, "Summarization of General-Knowledge-Education Research in China in Recent 10 Years,"Theory and Practice of Education, Vol. 23, No. 10, pp. 12-14, October 2003.

[4] Fan, Xiaojie, "The Statistical Analysis of Research Papers on General Education in China (19942006) "“ Journal of Higher Education in Science \& Technology, Vol. 267, No. 1, pp. 49-51, January 2007. 
[5] Le, Yi, " The Drawback of the College General Education Research in China since the 1990s," Modern University Education, Vol. 23, No. 3, pp. 35-40, March 2007.

[6] Xu, Dayan, "The Research on the Current Status and its Solutions of the Teaching of General Education Curriculum in University-Survey Based on the Teaching of General Education Curriculum in the Shantou University," Shantou: Shantou University, pp. 4-6, 2009.

[7] Li, Huichun, "A Study about the Status of the General Educational Curriculum Provision of Chinese Universities," Fudan Education Forum, Vol. 28, No. 4, pp. 21-27, April 2007.

[8] Pang, Haishao, "The Difficult Situation of the Construction of General Education Curriculum," Jiangsu Higher Education, Vol. 26, No. 2, pp. 63-66, April 2010.

[9] Feng, Ying, "Review of College General Education Curriculum in China in the Recent 20 years," Heilongjiang Education (Higher Education Research \& Appraisal), Vol. 67, No. 1, pp. 54-57, January 2012.

[10]Lv Linhai, Wang Xia, "Student Satisfaction Investigation on the Implementation of College General Education Curriculum in China ," Jiangsu Higher Education, Vol. 28, No. 3, pp. 66-69, March 2012.

[11]Li Ying, Yang Fengmei, Li Yan, "The Exploration of College General Education Courses,'Education and Vocation, Vol. 96, No. 24, pp. 118-120, December 2012. 